\title{
Detection of Small Wetlands with Multi Sensor Data in East Africa
}

\author{
Emiliana Mwita $^{1 *}$, Gunter Menz ${ }^{2}$, Salome Misana ${ }^{3}$, Pamela Nienkemper ${ }^{4}$ \\ ${ }^{1}$ Department of Geography, Dares Salaam University College of Education, Dares es Salaam, Tanzania \\ ${ }^{2}$ Department of Geography, Remote Sensing Research Group, University of Bonn, Bonn, Germany \\ ${ }^{3}$ Department of Geography, University of Dar es Salaam, Dares es Salaam, Tanzania \\ ${ }^{4}$ Center for Development Research (ZEF), Bonn, Germany \\ Email: *emmyrh@yahoo.com,g.menz@geographie.uni-bonn.de,smisana@udsm.ac.tz,pam-n@gmx.de
}

Received October 2, 2012; revised November 10, 2012; accepted November 18, 2012

\begin{abstract}
The dynamic nature and inaccessibility of wetland ecosystems restricts in situ data collection and promote the use of various remote sensing platforms. This is because of their ability to record large areas in comparatively short time periods and map physically unreachable areas. Sensors in the optical and microwave range of the electromagnetic spectrum play a critical role in wetlands detection and delineation, as they complement each other in data collection. This study examined the potential of optical and microwave remote sensing in detecting the diversity of small wetlands $(<500 \mathrm{ha})$ in the semi-arid and sub humid parts of Laikipia and Pangani plains and the humid parts of Mt. Kenya and Usambara highlands in Kenya and Tanzania, respectively. An intensive field survey was conducted to supplement the remotely sensed data. Decision tree, supervised and unsupervised classification techniques, facilitated the detection of floodplains and inland valley wetlands within the study sites. The results reveal that although optical and microwave data work effectively in the detection of wetlands the latter would be more effective in larger wetlands than those in the scope of this study.
\end{abstract}

Keywords: Wetlands Delineation; Microwave; Optical; Kenya; Tanzania

\section{Introduction}

Over the past few decades remote sensing has facilitated the study of wetlands and other environmental resources due to advancement in earth observation technology and data availability $[1,2]$. Satellite data have increasingly been used for mapping wetlands since they are in digital format and relatively easy to integrate into a geographic information system (GIS) [3]. Satellite remote sensing can be especially appropriate for wetland inventories and monitoring in developing countries, where funds are limited and little information is available on wetland areas $[3,4]$.

Optical remote sensing with different types of optical data like aerial photographs and satellite images has been widely used in wetland studies especially for the detection and mapping of wetlands $[1,3]$. Optical sensors such as Landsat or SPOT have proved to be suitable for identifying and monitoring wetland types, hydrologic regimes and landscape changes [4-6].

Since satellite data cover large areas, they are less costly and less time consuming when used for land classification for large geographical areas than aerial photo-

${ }^{*}$ Corresponding author. graphs $[7,8]$. Therefore wetlands and their surroundings can be easily mapped. However, the spatial resolution of satellite systems is often too coarse to derive land cover information of small wetlands. In addition, fewer types of wetlands can be discriminated by the use of these data compared to high resolution aerial photography. It is difficult to separate different wetland types from one another because of the similarity of their spectral signatures [9]. The spectral similarity between wetlands and other classes such as agricultural croplands and upland forests limits the accuracy in mapping with satellite imagery. In order to separate wetlands from uplands, it is usually advantageous to use satellite images from dates when the wetlands are at their highest water levels [3].

Many wetlands, however, are only flooded at certain times during the year. Thus given a satellite's fixed orbit and return interval, it is difficult to capture the optimal water conditions for wetland detection. In addition, lack of cloud free data often prevents the use of optical satellite data. Thus aerial photography is generally preferred for detailed mapping of wetlands, especially if many different types of vegetation must be mapped. Synergistic use of both satellite and aerial photography is, 
however, recommended for enhanced classification results [5].

By virtue of day and night observation and cloud penetration capability, the active microwave data from Synthetic Aperture Radar (SAR) offers high potential not only for mapping and monitoring the extent of land submergence but also in identifying the wetland vegetation [10]. In addition, SAR data have been found to be extremely useful in delineating flood water boundaries beneath vegetation canopies $[11,12]$. Another characteristic feature of microwave energy is the capability of penetrating clouds, smoke, light rain and haze, which implies that operations are almost irrespective of weather conditions [11-13].

In East Africa, little has been done in studying small wetlands using remote sensing. This is attributed to unavailability of resources in terms of data sets and finance, and lack of attention from researchers due to the size of wetlands despite their importance in the ecosystem and peoples livelihood $[14,15]$. This paper presents results of a study which was conducted in the Usambara highlands and Pangani lowlands as well as Mount Kenya highlands and Laikipia floodplain in Tanzania and Kenya respectively in order to: 1) detect different kinds of small wetlands (<500 ha) in the area with multi sensor data; 2) assess the potential and effectiveness of the sensors in detection of the wetlands. We hypothesized that small wetlands can be detected using multi-spatial and multispectral resolution data sets.

\section{Site Description}

\subsection{Location}

This study was conducted in the humid zones of the Mt. Kenya and the Usambara highlands, semi-arid Laikipia plain in Kenya and sub-humid parts of Pangani lowlands in Tanzania (Figure 1). The study area in Kenya lies bet-

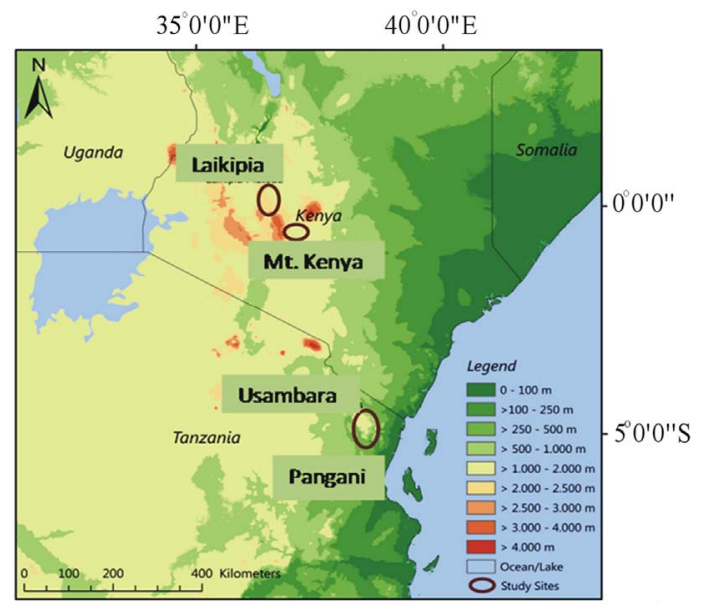

Figure 1. Location of the study sites in Tanzania and Kenya. ween longitude $36^{\circ} 12^{\prime} 17^{\prime \prime} \mathrm{E}$ and $37^{\circ} 9^{\prime} 55^{\prime \prime} \mathrm{E}$ and latitudes $0^{\circ} 7^{\prime} 28^{\prime \prime} \mathrm{S}$ to $0^{\circ} 33^{\prime} 5^{\prime \prime} \mathrm{S}$, rising from 1570 to $1835 \mathrm{~m}$ above sea level. In Tanzania, the study sites extend from $38^{\circ} 13^{\prime} 17^{\prime \prime} \mathrm{E}$ to $38^{\circ} 35^{\prime} 49^{\prime \prime} \mathrm{E}$ and $4^{\circ} 37^{\prime} 38^{\prime \prime} \mathrm{S}$ to $5^{\circ} 6^{\prime} 56^{\prime \prime S}$, at an altitude of between 280 and $1890 \mathrm{~m}$ above sea level. In the Kenyan sites, rainfall ranges between 400 and $1500 \mathrm{~mm}$ per annum while the rainfall in Tanzanian sites varies between 500 and $1200 \mathrm{~mm}$. All study sites have bimodal rainfall pattern with long rains between March and June, and short rains between October and December, though there is very high variability in the sub-humid and semi arid parts.

\subsection{Soils}

Soils in the study area vary a lot depending on the parent material. While the flood plains are dominated by unconsolidated sediment material, forming alluvial Luvisols and Fluvisols in the plains and Vertisols in the fringe areas, the highlands like Mt. Kenya are of volcanic origin, forming Andosols and Nitisols. The parent material of the Usambara Mountains is gneiss, which results in the formation of Ferralsols. Both, in Mt. Kenya region and in the Usambara highlands, the soils in the valley bottom lands are classified as Gleysols.

\subsection{Land Use and Land Cover}

Agriculture is the main economic activity in the study sites; field crops and horticulture are mainly produced (Figure 2). Horticulture is prevalent in the highland areas and is intensively done with year round crop rotation. Grazing is prevalent in the floodplains and is extensively done; in the highlands zero grazing is practiced. In the open water parts of the wetlands small scale fishing is practiced. Scattered settlements are found in the fringes of the wetlands. Coffee and other food crops are produced on the slopes of the highlands. Both exotic and natural forests exist on the upland slopes. Within the wetlands Cyperaceae (Cyperus papyrus), Typhaceae

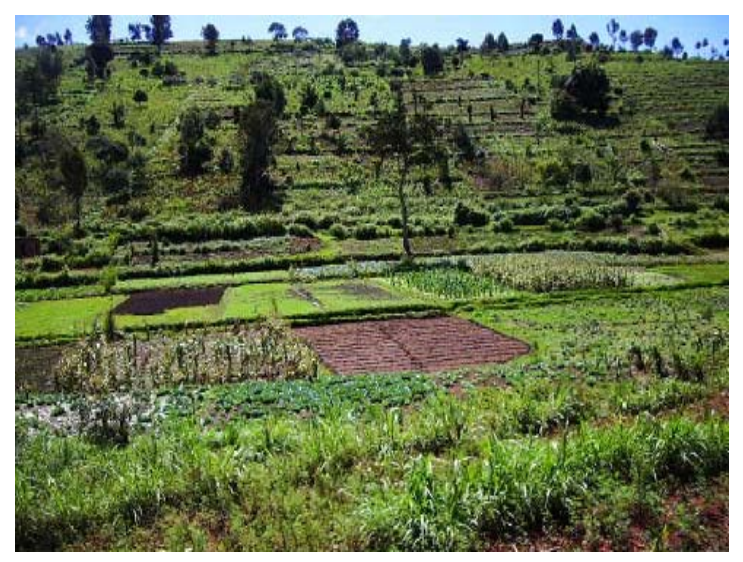

Figure 2. Wetland cultivation in Usambara highlands. 
(Typha capensis), Commelinaceae (Commelina benghalensis), Asteraceae (Pentodon pentandrus, Ageratum conyzoides) and other various shrub vegetation are the most common. The macrophytes are normally harvested for thatching, fodder and handicrafts.

\subsection{Wetlands in the Scope of This Study}

The diverse nature and character of wetlands has made it difficult for scientists to come up with single unifying definition of wetlands. The Ramsar Convention (2006) embraced this diversity in grouping together a wide variety of landscape units whose ecosystems share the fundamental wetland characteristic of being strongly influmenced by water. Because this definition is too broad, scientists have tended to define wetlands according to their needs. In this study the focus is on small wetlands, i.e., "land units of less than 500 ha that are characterized by permanent or seasonal flooding or by soil moisture availability higher than that of the surrounding uplands" [15].

\section{Data Sets and Methodology}

\subsection{Data Sets}

Different types of data have been used to accomplish the study; Landsat ETM+ $30 \mathrm{~m}$, the Shuttle Radar Topographic Mission (SRTM) $90 \mathrm{~m}$, aerial photographs, ALOS PALSAR and ENVISAT ASAR were the primary data sources used in this study (Table 1). Historical (1961) and current aerial photographs (2008/9) of various resolutions as indicated in Table $\mathbf{1}$ were acquired to capture different wetland types and size. We intended to use the latest available LANDSAT images but 2003 images were selected due to anomalies in the current LANDSAT 7 images, which are produced with gaps in scan lines. Since some of the wetlands were very small they couldn't be located in some of the images because of the gaps. ALOS PALSAR and ENVISAT ASAR were the main microwave data used. The images were obtained from European Space Agency. Most of the images were acquired between January and February, which is the peak dry season. During this time the differrence between upland and lowland wetlands is at the maximum. Ancillary data such as climate data, topographical maps and soil maps were also collected and used.

Ground-truth data on spatial location, land cover, agricultural land use and topographic characteristics were collected from field survey, which was conducted in the dry season (January \& February). Data were collected in terms of points using Personal Digital Assistant (PDA) GPS. In total 120 points were collected in the four sites. The points were used partly as training data for supervised classification and also for accuracy assessment.
Table 1. Data types and sources.

\begin{tabular}{|c|c|c|c|}
\hline Type of data & $\begin{array}{l}\text { Date of } \\
\text { acquisition }\end{array}$ & $\begin{array}{l}\text { Resolution } \\
\text { (m) }\end{array}$ & Source \\
\hline $\begin{array}{c}\text { Aerial } \\
\text { photographs }\end{array}$ & $\begin{array}{c}\text { Jan. } 1961 \\
\text { Feb. } 1975 \\
\text { Aug. 08/Feb. } \\
09\end{array}$ & $\begin{array}{c}20 \\
30 \\
0.25\end{array}$ & $\begin{array}{c}\text { Surveys } \\
\text { Kenya \& } \\
\text { Tanzania } \\
\text { Aerial } \\
\text { survey } \\
\text { Surveys }\end{array}$ \\
\hline Topographical maps & 1975 & $1: 50,000$ & $\begin{array}{l}\text { Kenya \& } \\
\text { Tanzania }\end{array}$ \\
\hline $\begin{array}{c}\text { LANDSAT ETM+ } \\
\text { Mt. Kenya highlands } \\
(169 / 060) \\
\text { Laikipia }(169 / 060) \\
\text { Usambara }(167 / 063)\end{array}$ & $\begin{array}{l}12-01-2003 \\
04-02-2003 \\
06-02-2003\end{array}$ & 30 & $\mathrm{USGS}^{1}$ \\
\hline $\begin{array}{c}\text { SRTM } \\
\text { Laikipia 44_12 } \\
\text { Mt. Kenya highlands } \\
\text { 44_13 } \\
\text { Usambara \& } \\
\text { Pangani 44_14 }\end{array}$ & & 90 & $\mathrm{CGIR}^{2}$ \\
\hline PALSAR & $\begin{array}{c}\text { Jan., Feb. \& } \\
\text { Mar. } 2008\end{array}$ & & $\mathrm{ESA}^{3}$ \\
\hline ASAR & Sept. 2006 & 30 & ESA \\
\hline
\end{tabular}

${ }^{1}$ United States Geological Survey; ${ }^{2}$ Consultative Group on International Agricultural Research; ${ }^{3}$ European Space Agency.

\subsection{Image Processing}

Historical aerial photographs were scanned at 750 dots per inch (DPI) and mosaics were made using Photoshop CS2 software. Topographical maps and LANDSAT images were used for geo-referencing the photographs in ERDAS imagine 9.3. Only the floodplain sites photographs were geo-referenced with root mean square error (RMS) of $0.5 \mathrm{~m}$. For the highlands geo-correction wasn't performed because the spatial resolution of the available SRTM-DEM was too course (90). The current aerial photographs were in digital format and had been rectified thus they didn't require pre-processing. The geometrical quality of the Landsat images was tested by superimposing topographical maps and aerial photograph images with a root mean square error between 0.45 and 0.88 . The SAR data were geo-coded and a digital elevation model (DEM) was used to simulate the topographic phase and transformation of data in radar geometry (slant to ground range map) to map coordinates.

\subsection{Data Analysis}

Different automated and semi-automated techniques [16] were used in the analysis of the data sets. Automated techniques included derivation of threshold values of the DEM slopes, calculation of Normalized Difference Vegetation Index (NDVI) and classification of optical data. Semi automated techniques involved image enhancement and on screen digitization of the enhanced images and aerial photographs. Image enhancement was applied to 
Landsat ETM+ using band combinations of ETM+ band 4, 3 and 5; 7, 4 and 2, and 3, 2 and 1. According to [16] and [3] those band combinations displayed in false colour composite (Red, Green and Blue) enhance wetlands depiction. Black and white and true colour aerial photographs, were visually interpreted for identification and location of the wetlands. Texture, pattern, colour, association and shape were the most important elements for wetlands identification. On screen digitization was also done to delineate the boundary of the wetlands.

Unsupervised Image clustering was conducted using Iterative Self Organizing Data Analysis (ISODATA) in ERDAS 9.3 as a first step in detection of the wetlands. Entire images were treated as one cluster; no signatures were used in the beginning. A number of natural clusters were generated after 80 iterations in a self organizing way. The ISODATA technique requires a large number of clusters and since only subset images were used and the basic aim was to separate wetlands from other land uses, only 12 clusters were produced. The convergence value was specified as 0.99 for all the data so that the utility would stop processing as soon as $99 \%$ was reached. The resultant clusters were assigned into one of the 12 classes (Figure 3), and reference images, maps and historical aerial photographs were used for preliminary cluster labeling. Supervised classification was carried out in ERDAS imagine. Sixty points collected in the field were used as training data and the rest (60 points) were used for accuracy assessment. Minimum distance to mean technique was used in the classification. At first,

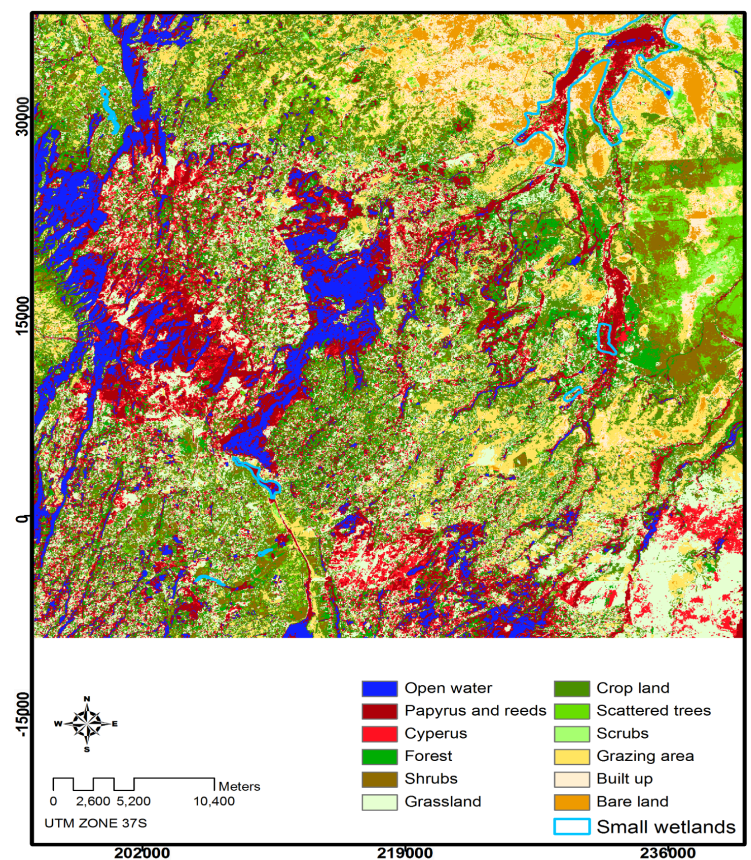

Figure 3. Unsupervised classification of the Laikipia plain using Landsat ETM+ image of 04-02-2003. twelve classes were separated from other land uses/cover. Two distinct classes, wetlands and non wetlands were generated.

For the dual polarized ALOS-PALSAR and ENVISAT-ASAR scenes, mean-value images were created by summing-up the two polarization channels (hh and hv) and calculating the mean digital value from the backscatter values in dB (Table 2). Furthermore, a transformation to band ratios was performed resulting in L-band $\sigma_{\text {hh }}^{0} / \sigma_{\text {hv }}^{0}$ and C-band $\sigma_{\text {hh }}^{0} / \sigma_{\text {hv }}^{0}$ ratio images. As indicated by [17] L-band $\sigma_{\text {hv }}^{0} / \sigma_{v v}^{0}$ ratio images are good indicators in the context of soil moisture estimation using imaging radars since surface roughness highly influences the feasibility of soil moisture detection. Image segmentation was performed by Definiens Developer 7. Five segmentation levels were performed in hierarchical manner using different scale parameters. Within the

Table 2. Overview of backscatter values $\sigma^{0}$ (in $\mathrm{dB}$ ) of different land cover classes.

\begin{tabular}{|c|c|c|c|c|}
\hline Data type & Land cover & $\begin{array}{c}\text { Min } \\
\mathrm{dB}\end{array}$ & $\begin{array}{c}\operatorname{Max} \\
\mathrm{dB}\end{array}$ & $\begin{array}{c}\text { Mean } \\
\mathrm{dB}\end{array}$ \\
\hline \multirow{5}{*}{$\begin{array}{c}\text { PALSAR } \\
\text { 2008-05-02 } \\
\text { hv-polarized }\end{array}$} & Water & -35.09 & -22.88 & -30.98 \\
\hline & Settlement & -32.24 & -12.032 & -20.12 \\
\hline & vegetation & -32.81 & -10.1 & -19.9 \\
\hline & Forest & -29.60 & -4.53 & -16.18 \\
\hline & Wetland & -36.84 & -14.77 & -24.14 \\
\hline \multirow{5}{*}{$\begin{array}{c}\text { PALSAR } \\
\text { 2008-05-02 } \\
\text { hh-polarized }\end{array}$} & Water & -27.43 & -10.80 & -22.58 \\
\hline & Settlement & -22.26 & 10.61 & -7.80 \\
\hline & vegetation & -23.10 & 12.40 & -9.89 \\
\hline & Forest & -21.75 & 7.52 & -7.84 \\
\hline & Wetland & -26.37 & -0.57 & -12.20 \\
\hline \multirow{5}{*}{$\begin{array}{c}\text { PALSAR } \\
\text { 2008-03-17 } \\
\text { hh-polarized }\end{array}$} & Water & -24.53 & -12.38 & -21.89 \\
\hline & Settlement & -23.95 & 11.38 & -10.44 \\
\hline & vegetation & -22.44 & 14.12 & -11.61 \\
\hline & Forest & -21.44 & 8.24 & -7.69 \\
\hline & Wetland & -23.27 & -4.40 & -13.75 \\
\hline \multirow{5}{*}{$\begin{array}{c}\text { PALSAR } \\
\text { 2008-01-31 } \\
\text { hh-polarized }\end{array}$} & Water & -24.99 & -13.61 & -20.93 \\
\hline & Settlement & -22.27 & 11.79 & -10.36 \\
\hline & vegetation & -26.11 & 5.38 & -12.29 \\
\hline & Forest & -26.80 & 7.30 & -7.82 \\
\hline & Wetland & -23.72 & -2.46 & -13.83 \\
\hline \multirow{5}{*}{$\begin{array}{c}\text { ASAR } \\
\text { 2006-09-21 } \\
\text { hv-polarized }\end{array}$} & Water & -22.90 & -11.42 & -17.87 \\
\hline & Settlement & -19.95 & 9.35 & -11.33 \\
\hline & vegetation & -22.40 & 7.354 & -10.30 \\
\hline & Forest & -20.88 & 1.54 & -9.89 \\
\hline & Wetland & -16.83 & -8.69 & -12.45 \\
\hline \multirow{5}{*}{$\begin{array}{c}\text { ASAR } \\
\text { 2006-09-21 } \\
\text { hv-polarized }\end{array}$} & Water & -14.25 & -5.67 & -11.47 \\
\hline & Settlement & -16.62 & 16.47 & -5.47 \\
\hline & vegetation & -18.90 & 10.69 & -5.01 \\
\hline & Forest & -19.29 & 6.31 & -5.27 \\
\hline & Wetland & -10.61 & -4.80 & -7.98 \\
\hline
\end{tabular}


segmentation process pixels are merged to image objects and pixel values are replaced by the mean value of the particular object [18].

Backscatter statistics of pixel and segment based images were examined by extracting different land cover types in optical data, in particular from Landsat scenes and topographical maps. Samples were selected carefully and were evenly distributed to capture the diversity of land uses and wetlands. The sample data were then saved as shape files in ArcMap then exported to ENVI as 'Region Of Interest' (ROI) to calculate statistics of each 'land cover class' that were later exported to Excel and Sigma plot 10.0 for visualization.

The extracted statistics were used in creating thresholds for decision tree classification for wetlands delineation. The classification was done using top down approach. The digital elevation model was applied separating the scene in two classes: potential wetland and non wetland (Figure 4). The resulting potential wetland class featured slopes lower than $6^{\circ}$ and non wetland class slopes above $6^{\circ}$. The underlying assumption was that wetlands generally occurred in level terrain. This is also supported by [18] who applied a slope threshold in their rule-based method for mapping wetlands in Canada. All areas where the slope exceeds $6^{\circ}$ were thus excluded at the root node.

The segmented $\mathrm{C}_{\text {mean }}$-band was applied with a co-domain ranging from -15.4 to $-8.9 \mathrm{~dB}$ (Figure 4). Values out of the range set up the second non-wetland class. After that the $\mathrm{C}_{\mathrm{hh}}$-band (co-domain -14 to -6.8 ) and the $\mathrm{C}_{\mathrm{hv}}$-band (co-domain -17.5 to -11 ) were applied. Backscatter values from areas that met either one of these conditions were considered to be potential wetland areas. Once more, the non-wetland classes were combined into one class resulting in a binary wetland/non-wetland classification of the C-band data.

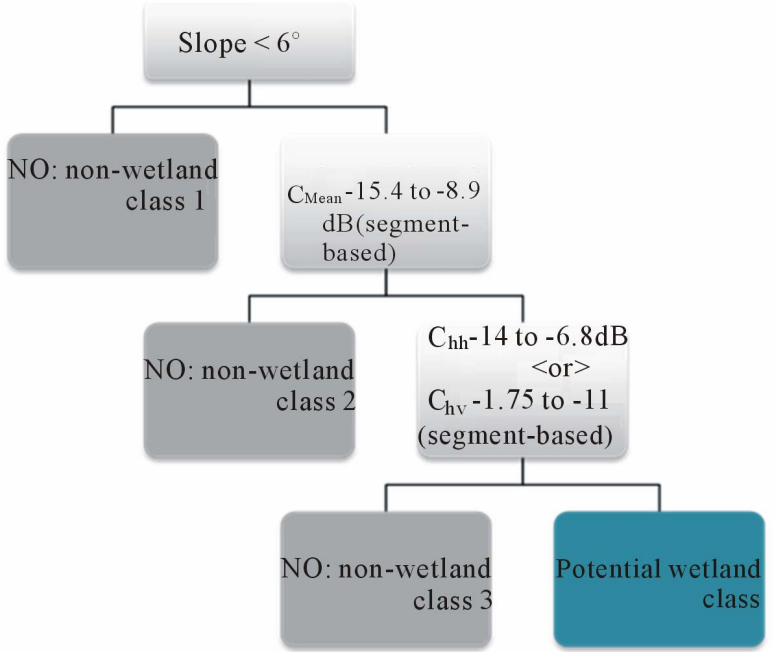

Figure 4. Design of the decision-tree classification based on C-band data (C-2).

\subsection{Accuracy Assessment}

The accuracy percentage of the classified Landsat images was determined by overlaying a total of 60 points over the delineated wetlands. The calculation was done using ERDAS imagine where the points were imported and their classes identified before the accuracy report was produced. For the microwave data, accuracy assessment was done using regions of interest (ROI) of different wetland classes derived from field work as well as in ENVI. The ROIs of various land covers were combined in one non wetland ROI with several polygons representatively distributed over the image.

\section{Results and Discussion}

\subsection{Detected Wetlands}

Two main wetlands types were identified by applying both automated and semi automated techniques. These were floodplains in semi-arid Laikipia plain and subhumid parts of Pangani lowlands and inland valleys in the humid zones of the Mt. Kenya and the Usambara highlands. In Landsat ETM+ images, floodplains were much easier to detect and delineate because they were larger in size than inland valleys, which were long, narrow and fragmented. Laikipia plain for example, was much easier to delineate because of its location in a semi arid area where it was surrounded by drier uplands, which reduced signature confusion with the riparian areas. In the Pangani plain some sites were very distinct, since they were wetter and covered with natural wetland vegetation like papyrus and reeds. Other sites were drier and covered with patches of short scattered grass and herbs, hence difficult to distinguish from bare surface. Inland valleys were first delineated with Landsat images but not much detail could be seen thus they were later adjusted by high resolution aerial photographs.

Both historical and current aerial photographs were very practical in marking the boundaries of both inland valleys and flood plains. Since the resolution of the current images was very high, the boundaries were clearly visualized and demarcated by digitization. Land use and land cover patterns of the wetlands were easily identified as they looked clearer in the photographs (Figure 5) than it was in the other data sets like Landsat images. Nevertheless, ground truthing was still necessary for verification of land use/cover patterns particularly in parts of wetlands that were accessible.

NDVI thresholds were very effective in wetlands detection. The values between $0.27-0.71$ clearly separated the Laikipia plain wetlands from other land cover and uses (Figure 6). For the Pangani plain, NDVI threshold of between 0.25 and 0.6 were responsible for delineation of wetlands. NDVI was. However, not very effective for 


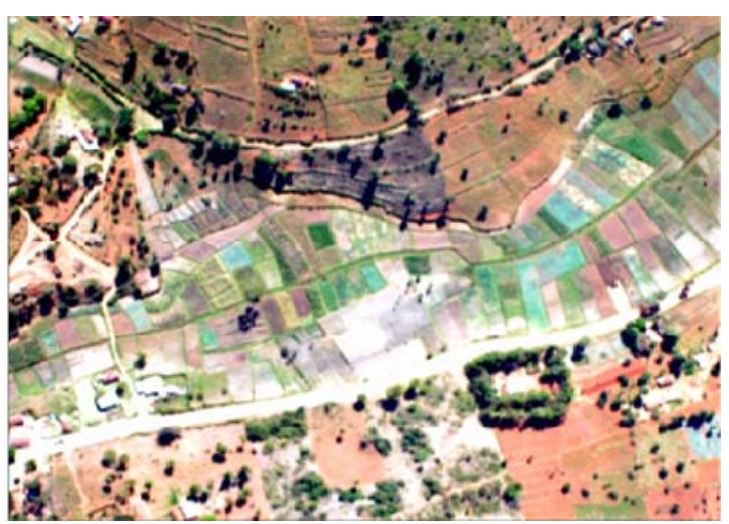

Figure 5. Subsections of aerial photographs of Mt. Kenya highland inland valley.

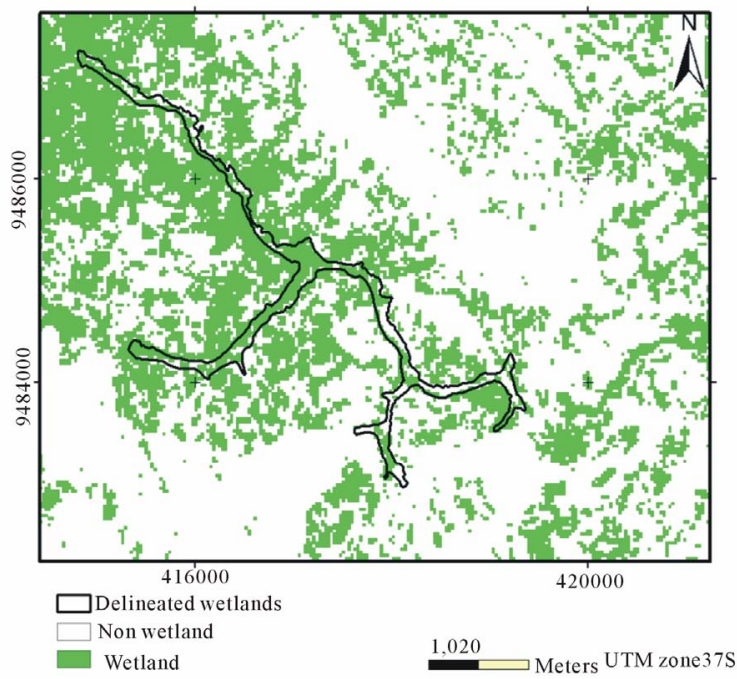

Figure 6. Wetland detection using NDVI threshold method for a section of Usambara highlands.

the detection of inland valleys in the highland sites probably because the images were from the dry season and most of the inland valleys had been cultivated. It is also possible that most of the crops were already harvested and the fields were bare and dry thus resembling the uplands or that the valleys were covered with herbaceous weeds, which were also in the uplands. Some of the inland valleys, which were covered by natural wetland vegetation like Cyperus and Typha spp. had slightly higher NDVI values. NDVI is very useful in the differenttiation of wetland vegetation and also for ditinguishing wetland boundaries from the surroundings [19,22]. In addition, even though in some cases the accuracies might be lower due to spectral confusion between the wetland and upland vegetation or sometimes crops cultivated, spectral data coming from red and near infrared region of the spectrum clearly distinguish between wetlands and non wetlands. In general, however, this index was not very effective for highland sites as the threshold values ranged between $0.04-0.32$, which is close to bare soil.

Wetlands with barren lands and/or sparse vegetation have lower NDVI as a result of soil moisture that is relatively higher than in the surrounding uplands [16]. When wetlands have natural vegetation or crops the NDVI will vary depending on vegetation density and vigor. NDVI is very useful in the differentiation of wetland vegetation and also for distinguishing wetland boundaries from the surroundings [22]. In addition, even though in some cases the accuracies might be lower due to spectral confusion between the wetland and upland vegetation or sometimes crops cultivated, spectral data coming from red and near infrared region of the spectrum clearly distinguish between wetlands and non wetlands.

With SAR data, wetlands were detected by the use of the backscatter signals of different land uses and the results of decision tree classification (Table 2 and Figure 7). In all the six scenes, the backscatter values of water and wetlands were clearly separable from other land uses. This is because areas with high soil moisture content have inherently lower backscatter values. In the dual polarised (hh) PALSAR scene acquired on 2nd May 2008, the water values ranged between -27.4 and $-10.8 \mathrm{~dB}$. Wetland values ranged between -26 and $-0.6 \mathrm{~dB}$ and when plotted they produced a bi-modal distribution, which can be explained by moisture variation within a given wetland.

Within the wetlands there were parts, which were very wet (permanently flooded) and others, which were drier (seasonally flooded). [20,23] had similar observations of the $\mathrm{L}_{\mathrm{hh}}$ backscatter of flood plains in West Africa and concluded that one peak was for wetter and another for

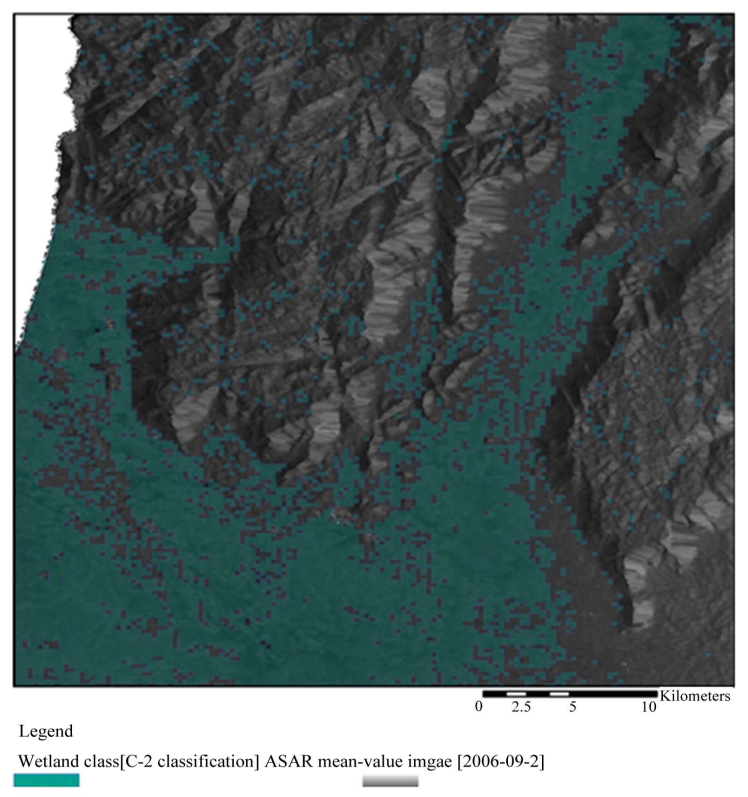

Figure 7. Illustration of the C-2 classification result of the Pangani plain. 
drier parts of the flood plains. In $\mathrm{L}_{\mathrm{hv}}$ of the same date the values for wetlands ranged between -38.8 to $14.8 \mathrm{~dB}$. In the January scene backscatter values for water and for the wetlands were lower and there was an overlap in backscattered values with other land uses. January is a drier month and wetlands are possibly similar to other vegetated and non overgrown areas. The long rains begin in March thus the values also slightly change but it is gradual since the soils are not completely saturated.

The backscatter values for C-band were lower than those of $\mathrm{L}$ band. For example the mean from water surfaces is $-17.9 \mathrm{~dB}$ for $\mathrm{C}_{\mathrm{hv}}$ and $-11.5 \mathrm{~dB}$ for $\mathrm{C}_{\mathrm{hh}}$ and the mean from wetland areas is $-12.5 \mathrm{~dB}$ for $\mathrm{C}_{\mathrm{hv}}$ and $-8 \mathrm{~dB}$ for $C_{h h}$. This scene was acquired towards the end of the dry season but the capability of C-band in detecting inundation is limited i.e., it cannot penetrate the vegetation cover if it is too dense. $[21,24]$ note that C-band SAR is primarily useful in sensing the characteristics of relatively sparse and short layers of vegetation and it is very useful in distinguishing herbaceous wetlands from clearing. Generally L-band SAR is seen to perform better in detection and differentiation of wetland types as also noted by [21-26] than C-band due to its ability to penetrate much into the vegetation canopy. Nevertheless, L-band data results were too generalized, i.e., a larger than expected wetland area was delineated.

\subsection{Accuracy of the Results}

The percentages of accuracy obtained from the classification of the images are presented in Table 3. In general producer accuracies are lower than user accuracies in microwave data for the non wetland class $(43.10$ $49.04 \%$ ). This indicates that there was some confusion in the classification, i.e., some ground truth points were misclassified (Non wetlands) with other land use classes (Wetlands). User accuracies are higher. That is to say the percentages of correctly classified wetlands within their given classes were higher. Overall classification accuracy was lower in microwave data than in optical data. LANDSAT image classification produced higher accuracies in Laikipia site for wetland class $(97.35 \%)$ and non wetland class $(86.36 \%)$. Overall classification using both supervised and NDVI classification was high $(96 \%$ \& $91.49 \%$ respectively) in Laikipia site. As already mentioned, this site, particularly Rumuruti test site, is located in the semi arid area and the surroundings are mostly bare. Thus the few wetlands existing in the area are identifiable without much spectral confusion. For the Pangani plain site the overall accuracies for NDVI and supervised classification are 82.26 and $80.85 \%$, respectively. User accuracy is very low $(50 \%)$ as compared to producer accuracy. This is caused by its location close to the Usambara highlands. The confusions are even higher
Table 3. Accuracies of classification of wetlands in percentage.

\begin{tabular}{|c|c|c|c|c|}
\hline \multicolumn{3}{|c|}{ NDVI threshold } & \multicolumn{2}{|c|}{$\begin{array}{l}\text { Minimum distance to } \\
\text { mean }\end{array}$} \\
\hline & Wetland & $\begin{array}{l}\text { Non } \\
\text { wetland }\end{array}$ & Wetland & $\begin{array}{c}\text { Non } \\
\text { wetland }\end{array}$ \\
\hline \multicolumn{5}{|c|}{ Pangani plain } \\
\hline Producer & 81.63 & 80 & 94.85 & 80.7 \\
\hline User & 98.53 & 83.75 & 50 & 81.48 \\
\hline \multicolumn{2}{|l|}{ Overall } & 82.26 & \multirow{2}{*}{\multicolumn{2}{|c|}{80.85}} \\
\hline & & ikipia plain & & \\
\hline Producer & 89 & 98 & 97.35 & 67.86 \\
\hline User & 98 & 100 & 92.44 & 86.36 \\
\hline \multicolumn{2}{|l|}{ Overall } & 96 & \multirow{2}{*}{\multicolumn{2}{|c|}{91.49}} \\
\hline & & ecision tree & & \\
\hline \multicolumn{5}{|c|}{ Pangani plain } \\
\hline \multicolumn{2}{|l|}{ L-band } & L-1 & \multicolumn{2}{|r|}{$\mathrm{L}-2$} \\
\hline Producer & 63.77 & 47.31 & 80.29 & 46.77 \\
\hline User & 88.73 & 79.74 & 88.35 & 88.61 \\
\hline Overall & & 53.88 & \multicolumn{2}{|r|}{59.47} \\
\hline C-band & & $\mathrm{C}-1$ & \multicolumn{2}{|r|}{$\mathrm{C}-2$} \\
\hline Producer & 45.4 & 45.04 & 73.48 & 43.16 \\
\hline User & 78.57 & 67.3 & 78.86 & 82.41 \\
\hline Overall & & 45.2 & \multicolumn{2}{|r|}{55.59} \\
\hline
\end{tabular}

with other land uses. This is a common problem with small wetlands classification using LANDSAT images as observed by $[3,19,22]$. C-band 1 and C-band2 classification produced overall classification of 45.2 and 55.59 respectively. The number of correctly classified wetland pixels was almost equal in $\mathrm{C} 1$ \& $\mathrm{C} 2 \quad(78.57 \%$ and $78.86 \%$ respectively). The number of correctly classified wetland ground truth points was higher than in non wetlands. Similarly in L band 1 and 2 wetlands were classified better than non wetlands. The user accuracy being $88.73 \%$ \& $88.35 \%$, respectively, the overall accuracy was also higher by almost $9 \%$ in $\mathrm{L}$ band $1 \%$ and $4 \%$ in $\mathrm{L}$ band 2 .

\subsection{Effectiveness of Data Sets Used in Wetland Detection and Delineation}

The data sets used demonstrated varied abilities in detection and delineation of wetlands due to their spatial and temporal resolutions as well sensor capabilities. In this study aerial photographs were very effective in both identification and discrimination of the wetland boundaries through visual observation and onscreen digitization. 
This is attributed to their higher resolution of $0.25 \mathrm{~m}$. The detailed information obtained was very useful in the classification process and differentiation of the land uses. The importance of aerial photographs in detection and delineation of small wetlands is also emphasized in the literature [3,19-21,24-26]. In addition to their usefulness in detailed mapping of the wetlands, they are indeed effective in boundary delineation. However, as observed by different authors like [21,26] aerial photographs are only suitable for a limited geographical area because they are relatively expensive. For this study, the aerial photographs covered only the areas of interest to minimise cost, thus their spatial coverage was relatively small as compared to Landsat images. In addition it is rarely possible to obtain time series aerial photographs of a given area, which are potentially necessary for wetlands detection. In the study sites in both countries, the only available aerial data were from early 1960s and 1970s; no current information was found in the archives. This necessitated an aerial survey to be undertaken to provide current information. Many of the wetlands that were found in the historical photographs couldn't be located in the current data sets. Generally aerial photographs enhanced delineation of inland valley wetlands because most of them were small and narrow and could only be covered by 3 or 4 pixels of the Landsat images.

Landsat images worked best in the floodplains basically because the floodplains were extensive in size as compared to inland valleys. In addition to spatial coverage the temporal resolution of the images assisted in validation of the results because it was possible to download anniversary images from previous years and compare them with the results found at the background as they didn't form important part of this study. With the NDVI images, the delineation was not clear as some parts of the sites were classified as non wetland although they were parts of the wetlands. This error of omission occurred because some of the wetlands were drier and sparsely vegetated or some parts were covered by open water. Wetlands with barren lands and/or sparse vegetation have lower NDVI as a result of soil moisture that is relatively higher than in the surrounding uplands [16]. When wetlands have natural vegetation or crops the NDVI will vary depending on vegetation density and vigour. The fact that optical data are much influenced by weather condition particularly clouds in tropical areas limited the use of Landsat images for only the dry season; wet season images were covered by clouds up to $80 \%$.

L-band data from both dry and wet season could not precisely distinguish the small wetlands of interest to this study. The delineation was too general as it included the whole flood plain. Within the flood plain, however, there were variations; some areas didn't qualify to be considered wetlands under the scope of the current study. The generalization could be a result of the slope threshold used for separation of wetlands from non wetland areas. As already noted slope thresholds do not work effecttively on plains. In addition to that, the SRTM (90 m) resolution was too course and this could have contributed to the poor-detection of the small wetlands. [27] In their study of remote sensing and wetland ecology in South Africa, used both Landsat and ENVISAT ASAR images. They found out that the Landsat images were efficient in delineation of both small and large wetlands but ASAR data detected only larger wetlands. They assumed that probably the small wetlands were lost during the preprocessing stage of the Radar images. It is, however, also important to note that the strengths of SAR as an appropriate tool for wetlands detection reside in the sensitivity of radar backscatter to the dielectric properties (soil and vegetation moisture content) and geometric (surface roughness) attributes of imaged surface; the higher the moisture content, the higher the dielectric constant and the stronger the signal and vice versa [12]. Thus the size of wetlands changes rapidly with occurrence of increased moisture content in the soil $[13,25]$. This could also explain why flood plains were easily detected because some parts were very wet and covered with natural wetland vegetation like papyrus and reeds compared to inland valleys.

\section{Conclusion}

This study has revealed the potentials of using multisensor data in wetlands inventory. The use of multi-spatial and multi-spectral resolution data for detection and delineation of small wetlands has proved to be of special significance. Optical data are capable of depicting smalller wetlands, which cannot be delineated by SAR data. On the other hand SAR data operates regardless of weather and are able to detect larger wetlands than the ones focused in this study. With SAR data, however, a slight change in soil moisture content may reduce or increase the wetland sizes. Due to the diverse nature of the small wetlands and environment in which they occur, single data types and methodology are insufficient for mapping them correctly. High spatial resolution data, however, remains ideal for small wetlands detection and delineation. The study offers spatial explicit data of particular wetlands that may later be used for their monitoring.

\section{Acknowledgements}

This research was supported by Volkswagen Foundation and realized under the Agricultural Use and Vul- nerability of Small Wetlands in East Africa (SWEA) project. The SWEA colleagues are highly appreciated for their support. We thank the reviewers for their critical observations and all those who contributed in any way to achi- 
eve the goals of the research.

\section{REFERENCES}

[1] P. Murphy, J. Ogilvie, K. Connor and P. Arp, "Mapping Wetlands: A Comparison of Two Different Approaches for New Brunswick, Canada," Wetlands, Vol. 27, No. 4, 2007, pp. 846-854. doi:10.1672/0277-5212(2007)27[846:MWACOT]2.0.CO;2

[2] B. W. Heumann, "Satellite Remote Sensing of Mangrove Forests: Recent Advances and Future Opportunities," Progress in Physical Geography, Vol. 35, No. 1, 2011, pp. 87-108. doi:10.1177/0309133310385371

[3] S. L. Ozesmi and M. E. Bauer, "Satellite Remote Sensing of Wetlands," Wetlands Ecology and Management, Vol. 10, No. 5, 2002, pp. 381-402.

doi:10.1023/A:1020908432489

[4] B. Haack, "Monitoring Wetland Changes with Remote Sensing: An East African Example," Environmental Management, Vol. 20, No. 3, 1996, pp. 411-419. doi:10.1007/BF01203848

[5] E. W. Ramsey III and S. C. Laine, "Comparison of Landsat Thematic Mapper and High Resolution Photography to Identify Change in Complex Coastal Wetlands," Journal of Coastal Research, Vol. 13, No. 2, 1997, pp. 281292.

[6] K. Kindscher, A. Fraser, M. E. Jakubauskas and D. M. Debinski, "Identifying Wetland Meadows in Grand Teton National Park Using Remote Sensing and Average Wetland Values," Wetlands Ecology and Management, Vol. 5, No. 4, 1997, pp. 265-273. doi:10.1023/A:1008265324575

[7] N. C. Davidson and C. M. Finlayson, "Earth Observation for Wetland Inventory, Assessment and Monitoring," Aquatic Conservation: Marine and Freshwater Ecosytems, Vol. 17, No. 3, 2007, pp. 219-228. doi:10.1002/aqc.846

[8] P. M. Mather, "Computer Processing of Remotely-Sensed Images: An Introduction,” John Wiley \& Sons Ltd., Hoboken, 1987.

[9] M. Gluck, R. Rempel and P. Uhlig, “An Evaluation of Remote Sensing for Regional Wetland Mapping Applications," Ontario Forest Research Institute, Peterborough, 1996.

[10] N. Baghdadi, M. Bernier, R. Gauthier and I. Neeson, "Evaluation of C-Band SAR-Data for Wetlands Mapping," International Journal of Remote Sensing, Vol. 22, No. 1, 2001, pp. 71-88. doi:10.1080/014311601750038857

[11] S. P. S. Kushwaha, R. S. Dwivedi and B. R. M. Rao, "Evaluation of Various Digital Image Processing Techniques for Detection of Coastal Wetlands Using ERS-1 SAR-Data," International Journal of Remote Sensing, Vol. 21, No. 3, 2000, pp. 565-579.

[12] F. M. Henderson and A. J. Lewis, "Radar Detection of Wetland Ecosystems: A Review," International Journal of Remote Sensing, Vol. 29, No. 20, 2008, pp. 5809-5835. doi:10.1080/01431160801958405

[13] T. M. Lillesand, R. W. Kiefer and J. W. Chipman, "Remote Sensing and Image Interpretation," 6th Edition,
Wiley and Sons, Hoboken, 2008.

[14] J. Franke, M. Becker, G. Menz, S. Misana, E. Mwita and P. Nienkemper, "Aerial Imagery for Monitoring Land Use in East African Wetland Ecosystems," IEEE International Geoscience and Remote Sensing Symposium 2009, Cape Town, 12-17 July 2009, pp. V288-V291.

[15] N. Sakané, M. Alvarez, M. Becker, B. Böhme, C. Handa, H. Kamiri, M. Langensiepen, G. Menz, S. Misana, N. Mogha, B. Möseler, E. Mwita, H. Oyieke and M. van Wijk, "Classification, Characterisation and Use of Small Wetlands in East Africa," Wetlands, Vol. 31, No .6, 2011, pp. 1103-1116.

[16] M. Islam, P. S. Thenkabail, R. W. Kulawardhana, R. Alankara, S. Gunasinghe, C. Edussriya and A. Gunawardana, "Semi-Automated Methods for Mapping Wetlands Using Landsat ETM+ and SRTM Data," International Journal of Remote Sensing, Vol. 29, No. 24, 2008, pp. 7077-7106. doi:10.1080/01431160802235878

[17] P. C. Dubois, J. Van Zyl and E. T. Engman, "Measuring Soil Moisture with Imaging Radars," IEEE Transactions on Geoscience and Remote Sensing, Vol. 33, No. 4, 1995, pp. 915-926.

[18] J. Li and W. Chen, "A Rule-Based Method for Mapping Canada's Wetlands Using Optical, Radar and DEM Data," International Journal of Remote Sensing, Vol. 26, No. 22, 2005, pp. 5051-5069. doi: $10.1080 / 01431160500166516$

[19] R. W. Kulawardhana, P. S. Thenkabail, et al., "Evaluation of the Wetland Mapping Methods Using Landsat ETM and SRTM Data," Journal of Spatial Hydrology, Vol. 7, No. 2, 2007, pp. 62-96.

[20] N. van de Giesen, M. Owe, K. Brubaker, J. Ritchie and A. Rango, "Characterization of West African Shallow Flood Plains with L-and C-Band Radar," Remote Sensing and Hydrology 2000, Santa Fe, 2-7 April 2000, pp. 365-367.

[21] J. Whitcomb, M. Moghaddam, K. McDonald, J. Kellndofer and E. Podest, "Mapping Vegetated Wetlands of Alaska Using L-Band Radar Sattelite Imagery," Canadian Journal of Remote Sensing, Vol. 35, No. 1, 2009, pp. 54-72. doi: $10.5589 / \mathrm{m} 08-080$

[22] K. C. Slatton, M. M. Crawford, J. C. Gibeaut and R. Gutierrez, "Modeling Wetland Vegetation Using Polarimetric SAR," International Geoscience and Remote Sensing Symposium, 1996, Lincoln, 27-31 May 1996, pp. 263-265.

[23] Y. Yamagata and Y. Yasuoka, "Classification of Wetland Vegetation by Texture Analysis Methods Using ERS-1 and JERS-1 Images," International Geoscience and Remote Sensing Symposium, 1993, Tokyo, 18-21 August 1993, pp. 1614-1616.

[24] J. H. Everitt, C. Yang, R. S. Fletcher, M. R. Davis and D. L. Drawe, "Using Aerial Color-Infrared Photography and QuickBird Satellite Imagery for Mapping Wetland Vegetation," Geocarto International, Vol. 19, No. 4, 2004, pp. 15-22. doi:10.1080/10106040408542323

[25] J. G. Lyon, "Wetland Landscape Characterization," CRC Press, Boca Raton, 2001

[26] W. R. Niedzwiedz and S. S. Batie, "An Assessment of Urban Development into Coastal Wetlands Using His- 
torical Aerial Photography: A Case Study," Environmental Management, Vol. 8, No. 1984, pp. 205-213.

doi:10.1007/BF01866962

[27] E. R. De Roeck, N. E. C. Verhoest, M. H. Miya, H.
Lievens, O. Batelaan, A. Thomas and L. Brendonck, "Remote Sensing and Wetland Ecology: A South African Case Study," Sensors, Vol. 8, No. 5, 2008, pp. 3542-3556. doi: $10.3390 / \mathrm{s} 8053542$ 